\title{
THE ER DESIGN SIMULATION GAME: EXPERIENCE AND REFLECT
}

\author{
Helena Lidelöw ${ }^{1}$
}

\begin{abstract}
Most simulation games that exist are targeted towards experiencing and reflecting on Lean principles such as tact time, pull, Kanban, continuous improvements etc. The design phase in construction is characterised by information not being available, iterative work, specialized work tasks, and high uncertainty. The research aim is to develop and test a design simulation game that explains the design principles: lack of information, iterative work, and specialized work in order to let inexperienced people experience and reflect (ER) on the design phase.

The method to develop the ER design game was to alter an already existing production sequence simulation game developed to illustrate one-piece flow. Action cards were entered into the game, changing work tasks and their sequencing as the game progressed. The ER design game demonstrates the difficulties in characterising and improving the design flow, but it does not show any methods to improve it. Lack of information, iterative work, specialized work, stop-start effects, and tact time issues all surfaced during playing the ER design game. The time frame for the game set was 45 minutes, which makes it feasible to incorporate in Lean method training.
\end{abstract}

Keywords: Design simulation, Lean games, Lean simulation, Reflection.

\section{INTRODUCTION}

Lean principles can be applicable to many processes in construction, such as design, prefabrication, and on-site work. Experienced-based learning is a fundamental principle in Lean and this has spurred the development of many general Lean simulation games (Bicheno 2015), and also in Lean construction (e.g. Rybkowski et al. 2008, Tommelein et al. 1998). So far, there are few experience-based games that capture the discontinuous flow in construction design against the fondant of Lean principles.

The construction design phase is characterised by a discontinuous flow of information due to:

- the lack of or uncertainty in information

- iterative work flow due to new decisions by some actor

- specialized work tasks distributed on many actors preventing balancing of flow

Lean coaches are often trained in supporting either Lean production where the steady flow in a pre-set production framework is sought or in Lean construction where the temporary flow in a construction project targeted. Therefore, there is a need for a simulation game that illustrates the context of the construction design phase, while encouraging reflections on appropriate Lean strategies to improve flow in design work. The aim of this research is to develop and test a design simulation game that explains the design principles: lack of information, iterative work, and specialized work in order to let inexperienced people

1 Associate Professor, Division of Industrialized and Sustainable Construction, Department of Civil, Environmental, and Natural Resource Engineering, Luleå University of Technology, Luleå, Sweden, helena.lidelow@ltu.se 
experience and reflect on the design phase. The game is named the ER design game to signal that Experience and Reflection are the targets, but also to bring attention to the urgency of understanding a process that sets the limits for downstream operations.

\section{METHOD}

\subsection{The original game - the onset of development}

The ER design game was developed as a reaction to Lean training, where all the associates at a Swedish construction contractor were given mandatory training using an experiencebased game that gradually improved the precision and workflow of a production sequence. The original game had the following features:

- the production of 20-40 "products" consisting of LEGO® plates with pieces arranged in different patterns according to colour

- a known order sequence of products

- a fixed product design in five variants produced in a workflow with five stations

- the possibility to balance work between work stations

The target of the original game is to produce a set number of products (e.g. 24 pieces) within a time frame of 12 minutes with zero errors. By doing multiple rounds and reflecting between each round on the changes made in workflow, the participants experience work balancing, standardization, and continuous improvement using the Kata cycle (Rother 2009). The original game supports understanding of the workflow in a workshop environment with pre-defined products.

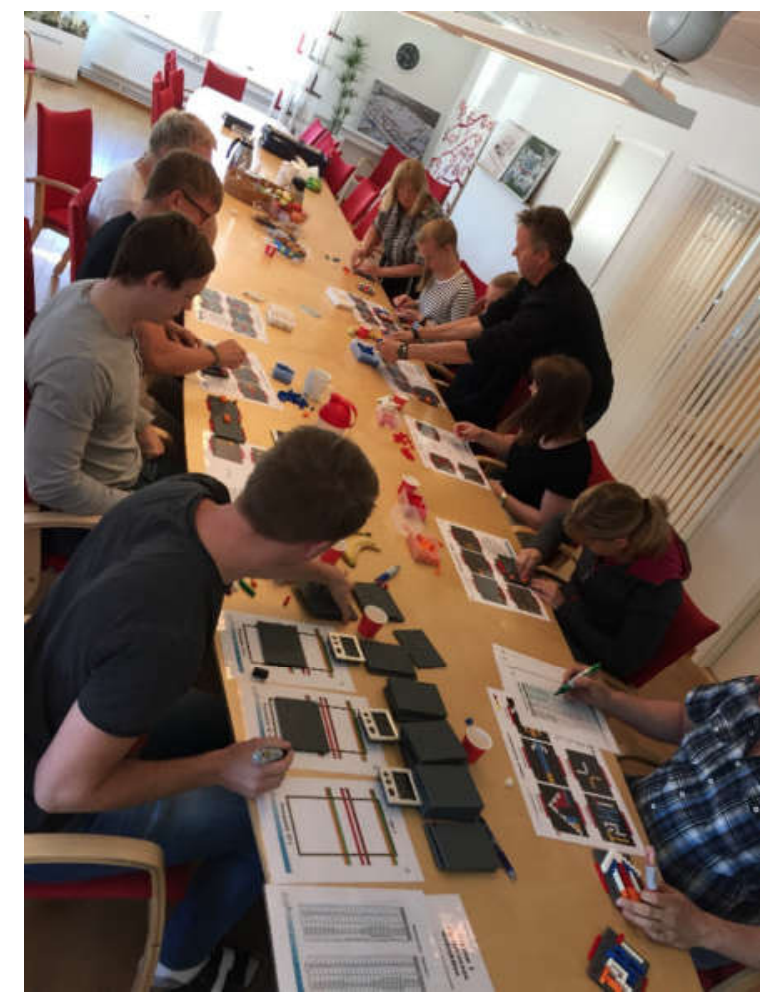

Figure 1: Playing the original game (Photo by Linda Rosén) 
The design department who participated in the training (the author is Head of Engineering for it) collectively expressed that "this was an interesting game, but it does not visualize our reality". As a response to that, the author suggested "OK, so let us change it and see if we can illustrate our point". Five persons where up for the challenge.

\subsection{The development of the ER design game}

To explore how the original game could be changed, two workshops and one documentation session was held. The group of five persons participated in the workshops, while the final documentation of the result was made by the author. Finally, the ER design game was tested: once by the design team and once by the top management team of the company.

The first workshop focused on altering the game to illustrate the experience of design flow. Very early, the lack of information emerged as a topic not covered by the original game. This was illustrated by obscuring half of the variant design so that players could not see how half their product was supposed to be constructed. To unlock this information, action cards where introduced into the game releasing design information at irregular intervals during the game.

Furthermore, the notion of specialization in design (e.g. Demir and Theis 2016) emerged as a hindrance to perform work balancing. The group decided to illustrate this by only allowing certain persons in the game to mount a specific colour of LEGO ${ }^{\circledR}$ blocks. When design information was released, only the person dedicated to the specific task could perform the needed work. Finally, three scenarios of design projects where organised with different levels of complexity, where the first focused the lack of information, the second additional orders, and the last introduced alterations in the design of the products.

The second workshop started with a test round of playing the prototype ER game from the first workshop. Reflections pointed out that the roles of each participant needed to be clarified, so each role was given a separate set of instructions. Furthermore, the three different design projects were further refined by removing actions that were too elaborate and instead focus on the basic understanding of design principles. Everything was documented in an Excel spreadsheet and stored together with the original game. An invitation was sent to the top management team of the company to participate in the game as part of Lean training. The invitation was accepted.

\subsection{Validation through playing}

The ER design game was played by the top management team (9 persons) consisting of Head of Market and Sales, the Logistics Manager, the Chief of Factory Operations, the Chief of Site Operations, the CEO, the Head of Administration, the manager of Human Resources, and two of the three Lean coaches. The Head of Engineering, which is the author of this paper, lead the game. The game was observed by one of the Lean coaches and one member of the development team from the workshops.

Three rounds were played with increasing degrees of complexity. The results and reflections from the game are presented in the Results and Analysis section.

\section{RESULTS AND ANALYSIS}

\subsection{Illustrating the lack of information}

In the design phase, the lack of information is a constant problem. It can have several sources e.g. lack of decisions from the client, lack of a technical solution, or the solution 
has not yet been developed. Whatever the cause, the result is that the work task cannot be finished. To illustrate this in the ER design game, parts of the product description was hidden to the players, shaded blue in figure 2. Each player sat down around a table with one game plan, figure 2, in front of him/her. The player should attach the blocks of his/her assigned colour and no others. The obscured information was released using an action card, issued after 3, 6, or 9 minutes into the game instructing players to reveal one or two of the hidden areas, figure 2. Therefore, the earliest finishing time for the game is $9+\mathrm{a}$ few minutes since 9 minutes is the last moment in time for releasing new information. An action card could read "We have decided that windows should have a new colour, please unlock areas labelled 1" or "The building permit is delayed, unlocking of areas labelled 2 is delayed 1.5 minutes".

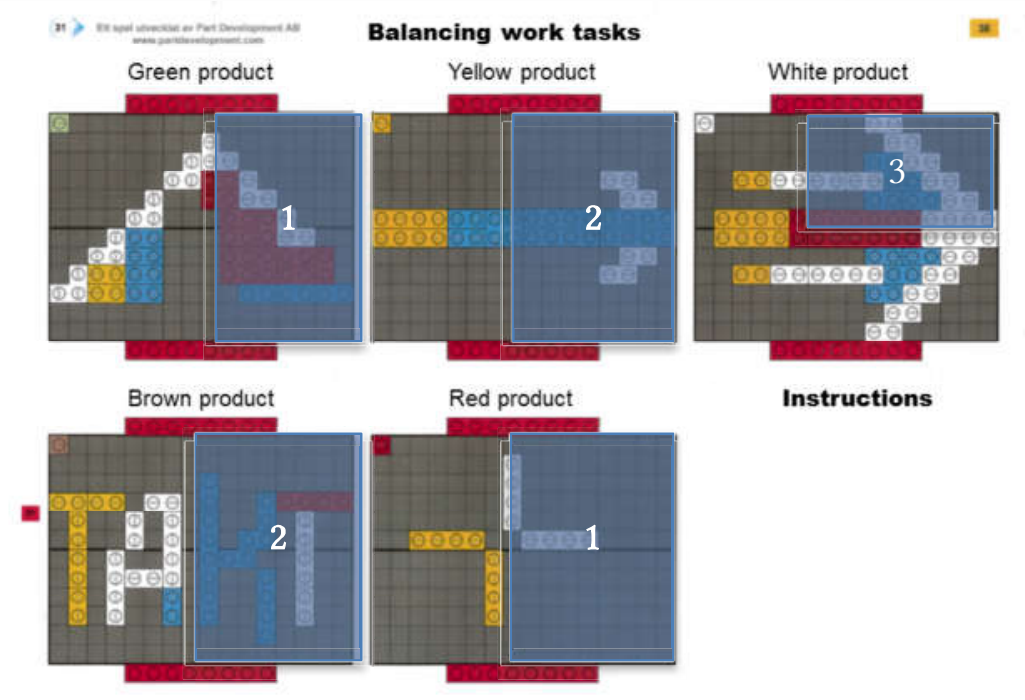

Figure 2: Game plan with obscured areas

When playing the validation round, the action cards pertaining to lack of information were read by the Head of Market and Sales as the client representative, since this emulates a realistic situation. The players' response to new information varied between the rounds. In the first round new information was needed to progress and people were eager to get new knowledge to move forward - thus giving new information fulfilled a need and was welcome. In the third and last round, the complexity was so high with iterative work being re-worked that the players met the release of new information with resistance, stating "We don't need anything more to do right now, please be quiet!".

\subsection{Illustrating iterative work}

Iterative work in design is often caused by changes in ideas and plans. They can pertain from the client or the designers themselves. Often iterations arise as a reaction to a design draft, which leads to a second or third draft being made. The iterations are sometimes necessary, but stifle flow of information from being smooth and predictable. To illustrate iterations in the ER design game, the action cards were not only releases of new information but also contained instructions about changes in the design. The changes were formulated as change orders e.g. by asking the team to produce something that was not originally decided or altering the design of the products by exchanging LEGO ${ }^{\circledR}$ blocks. 
As change orders were introduced some time into the game through the action cards, the game flow decreased and communication between participants increased. "If you redo your blocks, I'll go after you" was a typical comment showing the need for renegotiating the work sequence on the fly. This type of constant calibration with the surroundings is atypical for design work to avoid rework and stay tuned with the overall progress.

The resulting products of the game were approved by the client, which was an actor in the game. The client's job was to read the action cards at 3, 6, and 9 minutes into the game and accept or reject the finished products with alterations. When the client was satisfied with the batch delivery of all products, the game stopped.

\subsubsection{Illustrating work interruption}

In the setting of the company where the game was developed, a special circumstance occurs. The design team is given the task to support the factory production on a daily basis and if there are emergency problems, designers are summoned to the factory floor within 15 minutes to help figure out a solution to the emergency. In the game this was simulated by a factory action card entered into the game at random occasions.

The factory action card simply stated: "Emergency problem in the factory" and the instruction to the Chief of Factory Operations was to randomly remove one of the players from the game during 90 seconds to simulate that the player was now busy with something else and could not complete his part of the game. Since the game has specialized tasks (see 3.3) no other person can fill the gap during the 90 seconds of absence. When the player returned to the game, there was a start-up time for him/her to get into the flow again.

\subsection{Illustrating specialization}

From the validation round of the ER design game, it was clear that the restriction of specialization interacted with the iterative work. Specialization was emulated by restricting a single player to attach e.g. blue blocks. The idea was to emulate a situation where a team of drafters, structural engineers, and project leaders work together in design. If a change order in the ER design game requested that all blue blocks should be doubled, no one else in the game could complete that change order but the person assigned the blue blocks. The result was that the entire team at times was waiting for a single player to complete his/her task before delivering to the client. There were 7 appointed roles in the game, but the number of participants can be as low as 4 persons if the game leader takes on the roles of those not actually assembling blocks:

- Production preparation - starts the game by organising what products should be built according to instruction (which described a product mix, but not a sequence)

- Client - reads the action cards with new information to the team

- Production - reads the action cards where attention is taken from the team to attend to production problems

- Project leader - assembling yellow blocks

- Structural engineer - assembling blue blocks

- Designer - assembling red blocks

- Drafter - assembling white blocks

The team in the game was instructed to have a 'computer server' where the products in the game were stored while waiting for the next player to do his/her part. The server was simply a piece of paper placed in the middle of the table, emulating a computer storage 
facility. It emerged very early in the course of the game that someone needed to keep track of the order of products on the server, thus unintentionally demonstrating the need for 5S.

It was the responsibility of each individual of the game to keep track of the products on the server and complete the products with the individual's specific blocks when possible. During the course of the game, much of the communication concerned quality control of the products on the server with typical statements being "You can complete that one now, it is ready for you" or "Take these two before those three, so I can work on them first" and finally "You have not completed the yellow blocks here, please redo the work". The visibility of the products as compared to the target design enabled these flow seeking communications to take place.

\subsection{Experiences and Reflections}

Between each round there was time allotted to reflect upon the experiences in the game. There were numerous statements that showed that the participants in the validation game actually experienced the situation in the design flow:

"How are we supposed to know what product to work on? There is no sequence."

This reflection was immediate in the first round of the game and resulted in the players inventing a system by themselves for how the products should preferably flow and be organised on the 'server'. This can be compared to the real-life situation where designers try to organise their work from conceptual to detailed questions, store their progress in predefined folder systems, and mark every drawing according to state.

"I had nothing to do, while you were struggling. Maybe I can help?"

This very kind offer was issued by one of the players sitting next to a hard working colleague. However, the specialization of work tasks prevented the balancing of work load and both of them were disappointed when they could not support each other.

"This is easy, I complete my work at even pace."

This comment was offered by the player placing the blue blocks between rounds 2 and 3 . He had the role of the structural designer. During the third round, his work load was doubled through an action card never revealed before:

"I should never have said that this was easy! Now I am behind all the time."

The game plan thus illustrated that the flow in design is uneven and at times extremely stressful on single persons. While he struggled, the change order simultaneously put one of the other players out of work by commanding that his blocks were to be removed.

"What did you say? What was the change order?"

The changer orders were not issued as visual instructions showing the final product look i.e. a new game plan as in figure 2 was not issued. Instead, the change orders were written on the action cards instructing e.g. that all white blocks should be removed and all blue blocks doubled. The players and the clients had to remember these changes by heart while continuing the game. This event illustrated two things: 1 . Change orders need reflection in the team before processing them and 2. Change orders are difficult to implement through the entire value chain. The work pace in the game decreased considerably after a change order.

"Well, I really think that the client can shut up now. We have enough work to do!"

This comment was offered in the last round of the game, just after a complicated action card had been entered into the game. It simulates the frustration that many designers feel 
when trying to fulfil client needs while struggling with maintaining an even work flow. It also reflects the reaction to uncertainty in information that is ever present during the design stage.

The Lean coaches that participated in the game were somewhat concerned that several of the basic principles they teach are not applicable or mal-functioning in the design phase. Their background was not in Lean Construction, but in Lean Production with experience from the manufacturing industries such as Scania, Volvo, and Astra Pharmaceuticals. The ER design game thus fulfilled a second need: that of illustrating to Lean experts that there are situations when basic Lean principles must be rethought. The design flow situation is presumably better approached by Last Planner (e.g. Fosse and Ballard 2016) or Agile Project Management methods (Beck et al. 2001; Demir and Theis 2016).

\section{CONCLUSION}

The research has succeeded in developing and testing a design simulation game that explains the design principles:

- lack of information

- iterative work

- $\quad$ specialized work

The game allows inexperienced people to experience and reflect on the logics of flow in the construction design phase. The time frame of the game is 45 minutes, which makes it feasible to complete in the time allotted for most training sessions. The ER design game can be played in sequence with basic Lean training explaining flow, work balancing etc. Since the ER design game questions many of the basic Lean principles, it is wise to have a good grasp of them first, before adding the level of complexity the design flow offers.

\section{ACKNOWLEDGMENTS}

The developers of this game were Lina Andersson, Peter Öberg, Peter Holmgren, Anton Möller-Andersen, and Jens Wennerberg together with the author of this paper, Helena Lidelöw. Thank you for your time, effort, and creativity!

Thank you also to the top management team and Lean coaches at Lindbäcks Bygg, Ojjebyn, Sweden, for playing with open minds and engaging in the ER design game.

\section{REFERENCES}

Beck, K. et al. (2001). Manifesto for Agile Software Development, http://Agilemanifesto.org, 2016-12-11.

Bicheno, J. (2015). The Lean Games and Simulations Book. 2nd edition, Picsie Books, ISBN 978-0-9568307-2-2.

Demir, S.T. and Theis, P. (2016). Agile Design Management - The Application of Scrum in the Design Phase of Construction Projects. In proceedings from IGLC-24, Boston, USA, July 2016.

Fosse, R. and Ballard, G. (2016). Lean Design Management in Practice with the Last Planner System. In proceedings from IGLC-24, Boston, USA, July 2016.

Rother, M. (2009). Toyota Kata. 1st edition, McGraw-Hill, ISBN 978-0-0716352-3-3. 
Rybkowski, Z.K., Wong, J.-M., Ballard, G., and Tommelein, I.D. (2008). Using Controlled Experiments to Calibrate Computer Models: The Airplane Game as a Lean Simulation Exercise. In proceedings from IGLC-16, Manchester, UK, July 2008.

Tommelein, I.D., Riley, D., and Howell, G.A. (1998). Parade Game: Impact of Work Flow Variability on Succeeding Trade Performance. In proceedings from IGLC-6, Guarujá, Brazil, July 1998. 